\title{
Lung Squamous Cell Carcinoma
}

National Cancer Institute

\section{Source}

National Cancer Institute. Lung Squamous Cell Carcinoma. NCI Thesaurus. Code C3493.

A carcinoma arising from squamous bronchial epithelial cells. It may be keratinizing or non-keratinizing. Keratinizing squamous cell carcinoma is characterized by the presence of keratinization, pearl formation, and/or intercellular bridges. Non-keratinizing squamous cell carcinoma is characterized by the absence of keratinization, pearl formation, and intercellular bridges. Cigarette smoking and arsenic exposure are strongly associated with squamous cell lung carcinoma. 